\title{
Toward an understanding of the perpetuation of the agent of tularemia
}

\section{Sam R. Telford III* and Heidi K. Goethert}

Division of Infectious Diseases, Cummings School of Veterinary Medicine, Tufts University, North Grafton, MA, USA

\section{Edited by:}

Anders Sjostedt, Umeå University,

Sweden

Reviewed by:

Raquel Escudero, Institutes of Health

Carlos III - National Center of

Microbiology, Spain

Jeannine Petersen, Centers for

Disease Control and Prevention, USA

\section{*Correspondence:}

Sam R. Telford III, Division of Infectious

Diseases, Cummings School of

Veterinary Medicine, Tufts University,

200 Westboro Road, North Grafton,

MA 01536, USA.

e-mail: sam.telford@tufts.edu
The epidemiology of tularemia has influenced, perhaps incorrectly skewed, our views on the ecology of the agent of tularemia. In particular, the central role of lagomorphs needs to be reexamined. Diverse observations, some incidental, and some that are more generally reproducible, have not been synthesized so that the critical elements of the perpetuation of Francisella tularensis can be identified. Developing a quantitative model of the basic reproduction number of $F$. tularensis may require separate treatments for Type $A$ and Type $B$ given the fundamental differences in their ecology.

Keywords: tularemia, perpetuation, basic reproduction number, ecology

\section{INTRODUCTION}

The ecology of tularemia is represented by a literature that reflects the diversity of this complex zoonosis. Like the literature of many other infections, the sheer volume of observations makes it difficult to organize and synthesize sets of working hypotheses for how the causative agent exists in nature. An organized understanding of tularemia ecology serves as the basis for developing public health interventions and to predict or explain changes in incidence or distribution. In addition, knowing how the agent is currently maintained in nature provides information that helps us to reconstruct its evolutionary history. We review herein features of tularemia ecology that are particularly critical and suggest lacunae that hinder us from distinguishing major themes from variations on themes. The reader is referred to excellent reviews of the subject by Hopla (1974), Friend (2006), and Petersen et al. (2009) for significantly more detail on the breadth and diversity of the ecological literature.

\section{GENERAL COMMENTS ON THE ECOLOGY OF INFECTIOUS AGENTS}

We use some basic terms and concepts in the population biology of infectious agents that help to organize our interpretation of the existing literature. Maintenance refers to the life cycle of the agent: how one infection gives rise to at least one other infection. Perpetuation is maintenance over larger periods of time. Perpetuation of zoonotic infections may involve a vector, an intermediary in the life cycle that imparts directionality to the agent. Hematophagous arthropods are vectors because they require blood and thus directly transport an infectious agent to a relevant host. In contrast, scalars may also maintain an agent, but there is no directionality; copepods containing Dracunculus medinensis nematodes, for example, are passively imbibed with water. Vectors may support biological transmission of an agent, a process that involves replication or developmental changes. Mechanical transmission is contaminative; no replication or change is implied.

Vectorial capacity (Spielman and Rossignol, 1984) refers to the sum of vector traits that ensures that the basic reproduction number (BRN) of an infection exceeds unity and comprises competence (ability to support replication and effectively deliver the agent) as well as factors such as abundance, longevity, and narrowness of host range. A mosquito that requires a large dose of pathogen and rarely passes it during feeding has poor vector competence and thus might not contribute much to BRN, but even a highly competent vector (agent replicates well and is readily ejected during feeding) can have poor vectorial capacity if it feeds only on an animal that is a "dead end" host for the pathogen. The central question in the ecology of infectious agents is to describe how an agent ensures that BRN > 1 (Anderson and May, 1981); BRN < 1 implies unstable transmission and extinction. Quantitative modeling of BRN helps to synthesize diverse field observations and rank the contributions of factors and influences.

Basic reproduction number models may be developed from simple flow charts representing the presumed life cycle of the infectious agent; boxes can be outcomes (e.g., number of non-immune hosts) and arrows are processes (e.g., infection). Such compartmental models (Figure 1) can then be quantified by expressing the transitions between boxes as differential equations. We could adopt for the purposes of constructing a general tularemia model conditions similar to that for pasteurellosis in mice (Anderson and May, 1979). The agents of tularemia and pasteurellosis are categorized as microparasites: they are physically small with short generation times; they have a high replicative rate within a host; they tend to induce immunity to reinfection in survivors; and, the duration of infection is short relative to host lifespan. In addition, these infections may modify the demography of their host. If for the purposes of constructing a model, we 


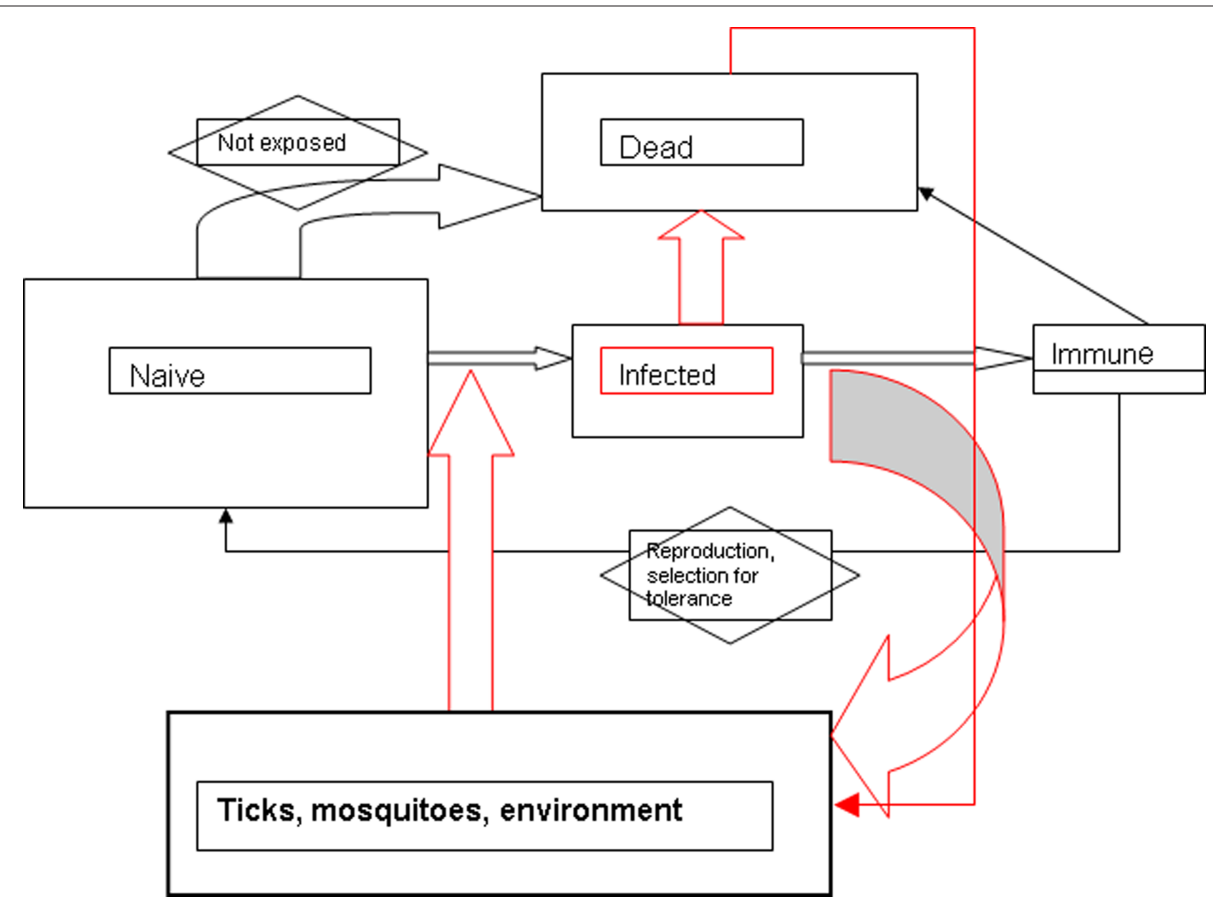

FIGURE 1 | Flow chart ("compartmental model") for general model of $\boldsymbol{F}$ t tularensis perpetuation. Rectangles represent hosts; size of rectangle might represent magnitude of host population. Red lines or arrows represent path taken by $F$. tularensis. Mode of transmission is a black box which comprises multiple factors. No time scale is implied in this simple model.

assume that the only mode of tularemia transmission is direct (no vectors; transmission by contact with, inhalation of or ingestion of saliva, excreta, or blood), then model development may proceed as outlined in Anderson and May (1979). The model then distils down to critical variables such as absolute number of susceptibles (noninfected); number that are infected; number immune; the natural mortality rate of the host population; the rate of introduction of susceptibles (immigration, birth); and a measure of the acquisition of infection (contact rate of susceptibles with infected). Even at this rudimentary level of discussion, we can see how difficult it would be to have an empirical basis for the model: we still debate the identity of the reservoir host for Francisella tularensis - or whether the reservoir might be environmental - and even if we assumed a specific animal, would we have data on its demography, behavior (contact between individuals), or prevalence of infection? However, by constructing such models, we can prioritize the field observations required for us to refine and validate the models, which summarize our current understanding of the life cycle. Resources should be expended in describing the circumstances of acquiring infection over determining the number of infected hosts, for example, because in the model the process drives the outcome.

\section{THE ROLE OF RABBITS IN TYPE A ECOLOGY: CONFLATION WITH EPIDEMIOLOGIC RISK}

Tularemia is a specific infectious disease due to Bacterium tularense and is transmitted from rodents to man by the bite of an infected bloodsucking insect or by the handling and dissecting of infected rodents by market men or laboratory workers. (Francis, 1922)
The first written account of tularemia in the US was in 1907 noting signs and symptoms compatible with tularemia in Native Americans who had handled jackrabbits (Barnes, 1928). A "plague-like" disease in ground squirrels was identified in 1909 during animal surveillance in California but microscopic observation of tissue sections demonstrated organisms inconsistent with the characteristic "safety pin" morphology of plague bacilli (McCoy, 1911). The bacterium was quickly cultivated and it was apparent that a new entity had been discovered (McCoy and Chapin, 1912). Although Pearse (1911) first described "deer fly fever" in Utah residents bitten by tabanid flies, Francis (1922) demonstrated its identity with the ground squirrel disease, and proposed the name "tularemia." He provided definitive evidence by isolating the agent from fly bitten humans, from jackrabbits, and ground squirrels. Francis also provided experimental evidence for transmission of tularemia by the bites of deerflies, lice, and bugs (Francis, 1922). Investigations of the Bitterroot Valley Rocky Mountain spotted fever epidemic in the 1920s isolated $F$. tularensis from the main RMSF vector, Dermacentor andersoni (Parker et al., 1924). Other human biting ticks (Dermacentor variabilis, Amblyomma americanum) were soon documented as vectors (Philip and Jellison, 1934; Parker, 1934). Therefore, within 20 years of its discovery as an infection of rodents in California, the most important aspects of the epidemiology (factors relating to human risk) of tularemia in the US had been described, as summarized by Francis' pithy statement, but taken together, the sum of knowledge would not allow quantitative modeling of BRN (ecology) for F. tularensis in any site. It is not clear that 80 years later that we have sufficient information to do so. 
Francis (1937) noted that $>90 \%$ of the $>6000$ tularemia case reports that he had compiled from 1924 to 1935 were associated with exposure to cottontail rabbits or hares, and this analysis surely helped to formally develop tularemia's reputation as "rabbit fever." It is possible that the strong rabbit association was due to an active market for rabbit meat in the north central states where there was a tradition of rabbit hunting (Yeatter and Thompson, 1952). This rabbit association, interestingly, obscured the fact that in the south central US, tick exposure accounted for $70 \%$ of all cases (Brooks and Buchanan, 1970) during the 1960s. Tularemia incidence in the US started to diminish in the 1960s (Boyce, 1975), perhaps as a result of a loss in popularity of rabbits as food and of hunting in general. It seems unlikely that the force of transmission of the agent diminished in nature during this time. The tick vectors (D. andersoni, D. variabilis, and A. americanum) for tick-transmitted tularemia in the US are the same as those for RMSF, which increased in incidence during the 1960s and 1970s (Childs and Paddock, 2002).

Russia and Japan had concurrently "discovered" tularemia (Francis, 1934; Pollitzer, 1967). Episodes of morbidity and mortality in hares were associated with an increase in the number of human cases of "yato-byo" and the disease could be acquired by skin contact with hare tissues (Ohara, 1926). Apparently, 90\% of all Japanese tularemia cases were associated with exposure to the hare Lepus brachyurus (Toyoshima and Ohara, 1967). Thus, in North America and Japan, during the very first decades of epidemiologic investigations of the disease, lagomorphs (rabbits and hares) were the main focus of attention. Researchers in the former Soviet Union were extremely active in investigations of tularemia, producing 1300 publications from 1928 to 1960 (Pavlovsky, 1966), and were the first to describe at least six perpetuation scenarios centered around habitat types (floodplain-swamp; meadow-field; forest; steppe; piedmont-river; and desert-floodplain); lagomorphs were requisites for none. Paradoxically, a hypothesis for the evolution of F. tularensis by Russia's most prominent tularemia researcher (Olsufiev, 1963) focused on associations with lagomorphs, mainly based on their great degree of "susceptibility and sensitivity" to infection as well as a scenario for the zoogeography of the steppes, which were thought by the former USSR workers to have been a pivotal habitat for tularemia.

Differences in distribution, ecology, biochemistry, and virulence led to the seminal classification of tularemia into distinct types (Olsufiev et al., 1959). Type A organisms (now known as F. tularensis tularensis) are prevalent in North America but not in Eurasia, are frequently transmitted by ticks, and may cause severe disease. Type B (F. tularensis holarctica) causes episodic outbreaks (epizootics) in beavers, muskrats, and arvicoline rodents in either North America or Eurasia, may be isolated from water or soil, and may cause a milder disease (Jellison et al., 1942; Parker et al., 1951). These eco-epidemiological paradigms retain tremendous utility and argue for modeling BRN separately.

The perception that tularemia was due to lagomorphs was largely the influence of Francis himself and also of William Jellison of the Rocky Mountain Laboratories, who compiled and interpreted the existing literature on tularemia biology in a seminal monograph (Jellison, 1974). Jellison argued that human risk and geographic distribution of North American tularemia was strongly associated with cottontail rabbits (Jellison and Parker, 1945; Jellison et al.,
1961). Cottontail rabbits are very susceptible to infection by Type A, dying within 7 days, and are large enough animals to attract attention when there is an epizootic, making them good sentinels for transmission activity. Furthermore, because of their value as food, their populations were a focus of attention by local residents and by state game management divisions: 25,000,000 rabbits were killed annually with a value of $\$ 5,000,000$ during the 1920 s (Henderson and Craig, 1932).

Whether cottontail rabbits are required for Type A BRN $>1$ remains unproven and requires further study. It may be that the question has been considered resolved due to conflating the requirements for maintenance with the proximal determinants for human exposure. Of course, human exposure (the subject of epidemiology) may provide clues to the mode of perpetuation (ecology) but this is not axiomatic. Zoonotic infections may exist in sites with no implied human risk in the absence of an effective epidemiological "bridge." The classical theory of natural nidality (Pavlovsky, 1966) posits that most zoonotic agents exist in longstanding foci that comprise optimal physical (weather, geology) and biological (fauna, flora) associations and that humans only become aware of their existence when they intrude. Accordingly, rabbits and hares may only be the epidemiological bridge and are not necessarily an element of natural focality.

The concept of rabbits as central to Type A ecology was bolstered by the identification of the rabbit tick, Haemaphysalis leporispalustris, as an effective enzootic vector (Parker 1934). These ticks are widely distributed across North America and their feeding is focused primarily on lagomorphs. Narrowness of host range (bites focused on relevant hosts) greatly contributes to vectorial capacity and BRN (Spielman and Rossignol, 1984). These ticks transmit F. tularensis and pass the agent by inheritance (transovarial transmission; Parker 1934); presumed Type A isolates were made from field collected H. leporispalustris (Philip and Parker, 1938). Rabbits may be infested by hundreds of these ticks and all stages may infest a rabbit simultaneously, thereby providing an opportunity for non-systemic (co-feeding) transmission (Randolph et al., 1996). Thus, rabbits and rabbit ticks could serve to powerfully maintain Type A. In addition, because subadults (larvae and nymphs) of this tick will infest ground-inhabiting birds, including those that migrate, the agent could be readily transported. Rabbit ticks range from Alaska to Argentina, reflecting such transport. This fact begs the question: why has F. tularensis not been detected in Latin America south of Mexico, particularly given the presence of rabbits throughout South America?

The central importance of rabbits and their ticks in Type A ecology is not supported by recent studies on Martha's Vineyard $(\mathrm{MV})$. This is the only site in the US which has endemic primary (inhalational) pneumonic tularemia (Matyas et al., 2007); of more than 100 tularemia cases reported from MV from 2000 to 2010, nearly two-thirds have been pneumonic. Case control studies demonstrate that landscapers are the major risk group and use of lawnmowers or leaf blowers are the main risk factors, suggesting environmental contamination. Exposure to ticks or rabbits was not associated with risk (Feldman et al., 2001) other than for one case who mowed over a rabbit. Landscapers there insist that they rarely mow over animal carcasses because they visually inspect properties prior to their activities to reduce 
hazard due to rocks and other debris. The nature of the fomites that served to infect these case-patients remains undescribed but unseen remnants of animal carcasses, animal feces, urine-soaked soil, ticks, tick feces, fleas, and contaminated water are possible sources. Why MV alone reports numerous pneumonic tularemia cases when tularemia is more prevalent in the south central US where lawnmowers are certainly used remains enigmatic. It is possible that the heavily salt-spray influenced landscape of the ocean facing southern edge of MV is more conducive to the agent remaining viable for a longer duration than elsewhere in the US (Berrada and Telford, in press).

Ecological studies, extended from Lyme disease surveillance starting in 1994, quickly suggested that dog ticks (D. variabilis) were important to Type A perpetuation (Goethert et al., 2004; Matyas et al., 2007; Goethert and Telford, 2009). Infection has been found in MV dog ticks every year to date, comprising a large degree of genetic heterogeneity (Goethert et al., 2009). Rabbits were indeed infected but virtually disappeared on MV, probably due to tularemia mortality; their disappearance did not influence the force of transmission of Type A, which continued to remain prevalent in dog ticks. Intensive studies of cottontail rabbits had been undertaken on Nantucket Island, which is visible from the eastern portion of MV. Rabbits attained densities of 15-20 per hectare and were heavily infested by H. leporispalustris (Telford and Spielman, 1989; Goethert and Telford, 2003). Evidence of tularemia had never been detected in more than 200 rabbits sampled on Nantucket, even though five human cases had been identified from 1990 to 2005. One of these cases was definitively associated with rabbits: a worker who had helped his colleague move a rabbit that had been mutilated by a lawnmower developed pneumonic tularemia (Goethert and Telford, 2005). This event demonstrated that even though Type A had been introduced at least once to Nantucket, despite the presence of dense rabbits and heavy $H$. leporispalustris infestations, the agent did not perpetuate. No mass die-offs of rabbits were noted during the year when the lawn mowing incident occurred, nor did active surveillance for rabbit carcasses by landscapers yield any evidence of mortality due to tularemia. There is one important difference in the ecology of Nantucket relative to MV: Nantucket lacks appreciable numbers of dog ticks (indeed, the tick may now be extirpated from that island due to the recent widespread use of topical anti-ectoparasiticides on dogs) because it does not have their reproductive hosts, skunks, raccoons, foxes, or coyotes. Although one exception to the rule of "rabbits maintain tularemia" does not necessarily invalidate the rule, we note that MV is one of few sites where longitudinal ecological studies have been undertaken and thus where incidental findings can be distinguished from general findings.

We suspect that rabbits are not necessarily critical to the BRN of Type A, or if they are, it is a function of local conditions. This dependence on local conditions, in fact, is the challenge of developing a quantitative model for the BRN of tularemia: should there be a general model, or should we approach the subject as did the researchers of the former USSR, focusing on independent natural foci? At one extreme, the 4 genotypes/subclades of Type A and 11 of Type B (Kugeler et al., 2009; Vogler et al., 2009) might each require a specific BRN model. But, a general model would have to assume that all elements for the ecology of Type A would apply to Type B and vice versa, not necessarily a good assumption.
Although our hypothesis is that dog ticks are critical to BRN on MV, experimentally infected as well as naturally infected ticks die more quickly than do those that are not (Reese et al., 2010; Goethert and Telford, submitted). A negative effect on fitness cannot be an adaptive strategy that would ensure BRN $>1$. These findings stand in contrast to our empirical observation of infected ticks each year, and suggest that there may be factors that mitigate the negative fitness of infection in nature.

\section{TYPE B ECOLOGY: DRIVEN BY WATER OR BY RODENTS?}

Tularemia in Eurasia and non-rabbit or tick associated infection in North America seem to have a strong environmental basis, acquired from agricultural activities such as hay threshing; from water contaminated by muskrats or water voles; or during the trapping of furbearers (Pavlovsky, 1966; Syrjala et al., 1985; Reintjes et al., 2002; Allue et al., 2008). In addition, transmission of the pathogen could occur via contamination of foodstuffs by urine or fecal material from infectious rodents (Karpoff and Antonoff, 1936; Parker et al., 1951). Experimental studies with voles suggested the possibility that some F. tularensis-infected animals developed a chronic nephritis and bacteriuria that could serve as a protracted source of environmental contamination (Bell and Stewart, 1975). Of particular interest was the suggestion that voles became partially immune due to low level infection resulting from cannibalism of tularemic carcasses and that this immunity allowed survival of the vole during subsequent infection, increasing the probability for shedding in the excreta. (Cannibalism of moribund cagemates is well known as a mode of transmission for Type A in the laboratory, Owen and Buker, 1956, and could be a complementary factor in perpetuation.) This suggestion of orally induced immunity has not been explored further but if confirmed could be a critical factor for the BRN of Type B, particularly in the context of environmental persistence.

The role of vectors in Type B perpetuation remains to be fully described. Ticks may be infected by Type B and are said to be the "reservoir" (Pavlovsky, 1966). In the former Soviet Union, 17 species of ixodid ticks have been found to be naturally infected (Balashov, 1972), presumably by Type B inasmuch as Type A is virtually restricted to North America. In addition, Type B is well known to be tick-transmitted in North America and both types may be present in ticks in the same site (Markowitz et al., 1985). Human cases certainly result from tick exposure but this mode of transmission is less common than exposure to furbearers or contaminated water (Pavlovsky, 1966). Dermacentor marginatus and Dermacentor reticulatus appear to be the main vectors there as well as into central Europe. As with Type A, Type B-infected D. marginatus or D. variabilis die more rapidly than do uninfected ticks (Petrov, 1960; Reese et al., 2010), which again raises the question of whether a non-adaptive trait may be associated with stable BRN.

Mosquitoes are strongly implicated as vectors in Sweden, given that tularemic ulcers are most frequently found on the upper back, neck, and ears of case-patients (Eliasson and Back, 2007), where mosquitoes are more likely to feed. In addition, the agent has been isolated from mosquitoes there (Olin, 1942) and recent studies provide evidence for mosquito larvae acquiring infection from water, perhaps by the ingestion of predatory protozoa (Mathisen et al., 2009). GIS studies of the Orebro endemic area in Sweden 
demonstrate that there is temporal-spatial association of incidence with mosquito breeding (Svensson et al., 2009). More analyses of the contribution of mosquitoes to BRN are needed. One recent study reported a third of mosquito pools to be infected in Alaska (Triebenbach et al., 2010) when tested by PCR, but this finding was at odds with the epidemiological evidence as well as with the difficulty of finding infection in animals. Older studies in Alaska failed to isolate F. tularensis from mosquitoes (Hopla, 1974) and thus it is not clear what the PCR findings represent; it should be noted that the assay that was used might also detect Francisella novicida. Future mosquito surveys should always attempt to confirm PCR findings with a complementary assay such as culture or even indirect immunofluorescence using monoclonal antibodies. At the very least, multiple gene targets should corroborate the findings. Definitive evidence for biological transmission by naturally infected mosquitoes might be provided by the use of deliberately placed sentinel mice but given the difficulties of animal experimentation in Sweden, not a likely approach. The recent suggestion that infectious agents may be detected by assaying sugar sources probed by mosquitoes (Hall-Mendelin et al., 2010) may be an effective alternative approach to demonstrating that naturally infected mosquitoes can transmit.

Given that mechanical transmission causes infection and thus $\mathrm{BRN}>1$, it might be considered academic to determine whether biological transmission occurs. But, the duration of mosquito infectivity would differ depending on whether it was mechanical or biological transmission, thereby impacting the magnitude of BRN. In addition, the possibility that mosquito larvae may acquire infection from water might greatly enhance BRN if those larvae became adult females that transmitted. Whether there is a main mode of perpetuation (e.g., ticks and rodents) with ancillary cycles (spillover into a water cycle, mechanical transmission by mosquitoes), whether it is the other way around (perpetuation within water and spillover into rodents and their ectoparasites) or whether there may be multiple parallel cycles in sites where there are ticks would be difficult to answer with field studies but might be facilitated by mathematical modeling of BRN. Such questions have more than just academic interest: if ticks and rodents drive the ecology of Type B, then intervention could be considered to reduce risk, for example, by rodent or tick control. If water drives the ecology, then risk reduction would have to focus on personal protection (e.g., with vaccination) given the difficulty of manipulating water ecosystems.

\section{WHY IS TULAREMIA RELATIVELY RARE?}

Both Type A and Type B are highly infectious and may be transmitted mechanically on the mouthparts of various hematophagous arthropods, or by contact with body or tissue fluids through abraded and even intact skin, and by ingestion, in addition to true biological (vector) transmission. Aerogenic infection was also very quickly noted by laboratory workers. Such a wide spectrum of modes of exposure and great infectivity helps to explain the wide range of kinds of animals known to be exposed or infected (Burroughs et al., 1945; Friend, 2006). It is likely that most of these animals do not serve as amplifying hosts ("reservoirs") that increase the BRN of the agent of tularemia, but are incidental "dead end" hosts. Many of the reports of an animal serving as host simply document exposure (seroreactivity) in a limited sample which does not allow inference about whether the exposure might be common over many sampling periods or among many sites. If an animal contributes significantly to BRN, it should do so for successive generations and in more than one site. This is the rationale for undertaking longitudinal ecologic studies: to determine whether an observation is incidental or is a generality.

The reason it is important to determine whether there is a main theme for perpetuation (one important reservoir host such as a lagomorph) as opposed to many themes (almost anything can serve as a reservoir) is that an ecological paradox otherwise exists: if virtually any hematophagous arthropod and vertebrate could maintain infection, then tularemia should be readily perpetuated and extremely common across the Holarctic. Thorough search of any site should document the presence of F. tularensis. From an epidemiological standpoint, tularemia is only moderately common, with global incidence in the range of 100-1000 cases annually (Paddock and Telford, in press). Tick surveys in known endemic sites generally record prevalence of F. tularensis infection in the range of $0.1-5 \%$ (e.g., Green, 1931; Hopla, 1960; Hubalek and Halouzka, 1997; Goethert et al., 2004) which is similar to that for tick borne encephalitis (TBE) virus in $I$. persulcatus complex ticks (Gresikova and Nosek, 1967; Korenberg, 1994; Schafer et al., 1999). TBE is considered to be a common tick borne infection, with 1000-10,000 new cases each year (Paddock and Telford, in press). TBE virus has a Palearctic distribution similar to that of tularemia. F. tularensis has been detected in I. ricinus, the main European vector of TBE. With the potential for transmission by mosquitoes, in addition to tick transmission and environmental exposure, tularemia risk (human incidence) over the Palearctic should approach or exceed that of TBE.

The question "why is tularemia not more common?" becomes even more vexing given the possibility of environmental persistence, that is, perpetuation that may be independent of vertebrate hosts. Surface water and sediment yielded indisputable DNA sequence evidence of contamination with Type B in Swedish endemic sites, even in years with little epidemiological activity (Broman et al., 2010). Infected carcasses contaminated water for 10 days and contaminated water stored in the cold infected animals after 2 weeks. Naturally contaminated mud remained infectious as long as 10 weeks (Parker et al., 1951). Experimental microcosm experiments demonstrated that $F$. tularensis in silt could infect animals for 2 months. About half of rodents immersed in contaminated water became infected with exposure to as few as 100-1000 cfu/mL (Pavlovsky, 1966), which appears to be large dose but the spleen alone of a mouse dying of tularemia may have $10^{10} \mathrm{cfu}$ (Molins et al., 2010) and it would not take many carcasses to contaminate a contained body of water. Indeed, many have speculated that environmental persistence depends on continual contamination by dead animals. However, water invertebrates such as shrimp or snails could retain viable organisms for 20 days (Mironchuk and Mazepa, 2002), and indeed, invertebrates were first described as contributing to F. tularensis survival within water by former USSR research (Pavlovsky, 1966). More recent reports (Anda et al., 2001) of crayfish infection suggest that additional surveys using modern methods are warranted. Even more interesting is the hypothesis 
that free-living amebae serve as hosts (Berdal et al., 1996; Abd et al., 2003; El-Etr et al., 2009), which would allow for even greater duration of persistence and even the possibility of amplification in the absence of vertebrates. In terms of BRN, environmental persistence within aquatic invertebrates or protozoa would have implications for ensuring that $\mathrm{BRN}>1$ when vertebrates are scarce but water contamination could serve to greatly increase BRN and trigger an epizootic or outbreak.

\section{PRIORITIES FOR TULAREMIA ECOLOGY RESEARCH}

The ecology of tularemia is sufficiently complex that limited resources for research should be targeted to the most relevant questions. Developing quantitative models of the BRN for tularemia, probably separately for Type A and Type B, would appear to be

\section{REFERENCES}

Abd, H., Johansson, T., Golovliov, I., Sandstrom, G., and Forsman, M. (2003). Survival and growth of Francisella tularensis in Acanthamoeba castellanii.Appl.Environ. Microbiol.69, 600-606.

Allue, M., Sopena, C., Gallardo, M. T., Mateos, L., Vian, E., Garcia, M. J., Ramos, J., Berjon, A. C., Viña, M. C., Garcia, M. P., Yanez, J., Gonzalez, L. C., Munoz, T., Andres, C., Tamames, S., Ruiz, C., Gómez Iglesias, L. A., and Castrodeza, J. (2008). Tularemia outbreak in Castilla y Leon, Spain, 2007: an update. Eurosurveillance 13, 18948.

Anda, P., del Pozo, J. S., Díaz García, J. M., Escudero, R., García Peña, F. J., López Velasco, M. C., Sellek, R. E., Jiménez Chillarón, M. R., Sánchez Serrano, L. P., and Martínez-Navarro, J. F. (2001). Waterborne outbreak of tularemia associated with crayfish fishing. Emerg. Infect. Dis. 7, 575-582.

Anderson, R. M., and May, R. M. (1979). Population biology of infectious diseases: part I. Nature 280, 361-367.

Anderson, R. M., and May, R. M. (1981). The population dynamics of microparasites and their vertebrate hosts. Philos. Trans. R. Soc. Lond. 210, 658-661.

Balashov, Y. S. (1972). A translation of bloodsucking ticks (Ixodoidea) vectors of diseases of man and animals. Misc. Publ. Entomol. Soc. Am. 8, 161-376.

Barnes, W. C. (1928). Rabbit fever or tularemia. Sci. Mon. 27, 463-469.

Bell, J. F., and Stewart, S. J. (1975). Chronic shedding tularemia nephritis in rodents: possible relation to occurrence of Francisella tularensis in lotic waters. J. Wildl. Dis. 11, 421.

Berdal, B. P., Mehl, R., Meidell, N. K., Lorentzen-Styr, A. M., and Scheel, O. (1996). Field investigations of tularemia in Norway. FEMS Immunol. Med. Microbiol. 13, 191-195.

Berrada, Z., and Telford, S. R. (in press). Survival of Francisella tularensis tularensis in brackish water. Arch. Microbiol. [Epub ahead of print].

Boyce, J. M. (1975). Recent trends in epidemiology of tularemia in UnitedStates. J. Infect. Dis. 131, 197-199.

Broman, T., Thelaus, J., Andersson, A. C., Bäckman, S., Wikström, P., Larsson, E., Granberg, M., Karlsson, L., Bäck, E., Eliasson, H., Mattsson, R., Sjöstedt, A., and Forsman, M. (2010). Molecular detection of persistent Francisella tularensis subspecies holarctica in natural waters. Int. J. Microbiol. 2011, 10.

Brooks, G. F., and Buchanan, T. M. (1970). Tularemia in United-States epidemiologic aspects in 1960s and follow-up of outbreak of tularemia in Vermont. J. Infect. Dis. 121, 357.

Burroughs, A. L., Holdenried, R., Longanecker, D. S., and Meyer, K. F. (1945). A field study of latent tularemia in rodents with a list of all known naturally infected vertebrates. J. Infect. Dis. 76, 115-119.

Childs, J. E., and Paddock, C. D. (2002). Passive surveillance as an instrument to identify risk factors for fatal rocky mountain spotted fever: is there more to learn? Am. J. Trop. Med. Hyg. 66, 450-457.

El-Etr, S. H., Margolis, J. J., Monack, D., Robison, R. A., Cohen, M., Moore, E., and Rasley, A. (2009). Francisella tularensis type A strains cause the rapid encystment of Acanthamoeba castellanii and survive in amoebal cysts for three weeks postinfection. Appl. Environ. Microbiol. 75, 7488-7500.

Eliasson, H., and Back, E. (2007). Tularaemia in an emergent area in Sweden: an analysis of 234 cases in five years. Scand. J. Infect. Dis. 39, 880-889.

Feldman, K. A., Enscore, R. E., Lathrop, S. L., Matyas, B. T., McGuill, M., Schriefer,

a priority because such models provide structure for observations. Critical life cycle breakpoints and influential variables can be hypothesized a priori and tested by field observations. Surveys should be undertaken to identify useful study sites where the agent is reliably detected and longitudinal observations (on a scale of years) may be undertaken. Cooperative agreements should be developed among researchers and long term funding jointly sought to support such studies. We have outlined some of the more interesting lacunae in our knowledge of tularemia ecology, and additional information for all of these would greatly enhance iterative refinements of BRN quantitative models in the future.

\section{ACKNOWLEDGMENT}

We are supported by NIH R01 AI 064218.

M. E., Stiles-Enos, D., Dennis, D. T., Petersen, L. R., and Hayes, E. B. (2001) An outbreak of primary pneumonic tularemia on Martha's Vineyard. N. Engl. J. Med. 345, 1601-1606.

Francis, E. (1922). Tularemia Francis 1921. A new Disease of Man. Hygienic Laboratory Bulletin Number 130 Washington, DC: Government Printing Office.

Francis, E. (1934). Tularemia. Sci. Mon 38, 476-479.

Francis, E. (1937). Sources of infection and seasonal incidence of tularaemia in man. Public Health Rep. 52, 103-113.

Friend, M. (2006). Tularemia. Reston, VA: U.S. Geological Survey, Circular 1297, 68 .

Goethert, H. K., Shani, I., and Telford S. R. III (2004). Genotypic diversity of Francisella tularensis infecting Dermacentor variabilis ticks on Martha's Vineyard, Massachusetts. J. Clin. Microbiol. 42, 4968-4973.

Goethert, H. K., and Telford, S. R. (2003). Enzootic transmission of Anaplasma bovis in Nantucket cottontail rabbits. $J$. Clin. Microbiol. 41, 3744-3747.

Goethert, H. K., and Telford, S. R. (2005). Tularemia, lawn mowers, and rabbits' nests-authors' reply. J. Clin. Microbiol. 43, 4304-4305.

Goethert, H. K., and Telford, S. R. (2009). Nonrandom distribution of vector ticks (Dermacentor variabilis) infected by Francisella tularensis. PLoS Pathog. 5, e1000319. doi: 10.1371/journal. ppat.1000319

Goethert, H. K., Saviet, B., and Telford, S. R. (2009). Metapopulation structure for perpetuation of Francisella tularensis tularensis. BMCMicrobiol.9, 147 doi: 10.1186/1471-2180-9-147

Green, R. G. (1931). The occurrence of Bact. tularense in the eastern wood tick, Dermacentor variabilis. Am. J. Hyg. 14, 600-613.

Gresikova, M., and Nosek, J. (1967). Isolation of tick borne encephalitis virus from Ixodes ricinus ticks in the Tribec region. Bull. World Health Organ. 36(Suppl. 1), 67-71.

Hall-Mendelin, S., Ritchie, S.A., Johansen, C. A., Zborowski, P., Cortis, G., Dandridge, S., Hall, R. A., and van den Hurk, A. F. (2010). Exploiting mosquito sugar feeding to detect mosquito-borne pathogens. Proc. Natl. Acad. Sci. U.S.A. 107, 11255-11259

Henderson, F., and Craig, E. L. (1932). Economic Mammalogy. Springfield, IL: Charles C. Thomas, 397.

Hopla, C. E. (1960). The transmission of tularemia organisms by ticks in the southern states. South. Med. J. 53, 92-97.

Hopla, C. E. (1974). "The ecology of tularemia," in Advances in Veterinary Science and Comparative Medicine, Vol. 18, eds C. A. Brankly and C. E. Cornelius (New York, NY/London: Academic Press), 18, 25-53.

Hubalek, Z., and Halouzka, J. (1997). Mosquitoes (Diptera: Culicidae), in contrast to ticks (Acari: Ixodidae), do not carry Francisella tularensis in a natural focus of tularemia in the Czech Republic. J. Med. Entomol. 34, 660-663.

Jellison, W. (1974). Tularemia in North America: 1930-1974. Missoula, MT: University of Montana.

Jellison, W., Kohls, G. M., Butler, W. J., and Weaver J. A. (1942). Epizootic tularemia in the beaver, Castor canadensis, and the contamination of stream water with Pasteurella tularensis. Am. J. Epidemiol. 36, 168-182.

Jellison, W. L., Owen, C., Bell, J. F., and Kohls, G.M. (1961). Tularemia and animal populations. Wildl. Dis. 17, 1-22.

Jellison, W. L., and Parker, R. R. (1945). Rodents, rabbits and tularemia in North America-some zoological and epidemiological considerations. Am. J. Trop. Med. 25, 349-362.

Karpoff, S. P., and Antonoff, N. I. (1936). The spread of tularemia through water, 
as a new factor in its epidemiology. $J$. Bacteriol. 32, 243-258.

Korenberg, E. I. (1994). Comparative ecology of Lyme disease and tick borne encephalitis in the former Soviet Union. Parasitol. Today 10, 157-160.

Kugeler, K. J., Mead, P. S., Janusz, A. M., Staples, J. E., Kubota, K. A., Chalcraft, L. G., and Petersen, J. M. (2009). Molecular epidemiology of Francisella tularensis in the United States. Clin. Infect. Dis. 48, 863-870.

Markowitz, L. E., Hynes, N. A., de la Cruz, P., Campos, E., Barbaree,J.M., Plikaytis, B. D., Mosier, D., and Kaufmann, A. F. (1985). Tick borne tularemia. An outbreak of lymphadenopathy in children. JAMA 254, 2922-2925.

Mathisen, P., Andersson, A. C., Backman, S., Lundstrom, J., Kouppa, K., Schafer, M., Thelaus, J., and Forsman, M. (2009). "Association and uptake of Francisella tularensis subspecies holarctica into mosquitoes," in Abstract P2-06, 6th International Conference on Tularemia (Berlin), 13-16.

Matyas, B. T., Nieder, H. S., and Telford, S. R. III (2007). Pneumonic tularemia on Martha's Vineyard: clinical, epidemiologic, and ecological characteristics. Ann. N. Y. Acad. Sci. 1105, 351-377.

McCoy, G. W. (1911). A plague like disease of rodents. Public Health Bull. $43,53-71$.

McCoy, G. W., and Chapin, C. W. (1912). Further observations on a plague-like disease of rodents with a preliminary note on the causative agent, Bacterium tularense. J. Infect. Dis. 10, 61-72.

Mironchuk, I., and Mazepa, A. V. (2002). Viability and virulence of Francisella tularensis subsp. Holarctica in water ecosystems (experimental study). $Z \mathrm{~h}$. Mikrobiol. Epidemiol. Immunobiol. 2, 9-13.

Molins, C. R., Delorey, M. J., Yockey, B. M., Young, J. W., Sheldon, S. W., Reese, S. M., Schriefer, M. E., and Petersen, J. M. (2010). Virulence differences among Francisella tularensis subsp tularensis clades in mice. Plos One 5(4). doi: 10.1371/journal.pone.0010205

Ohara, H. (1926). Experimental inoculation of disease of wild rabbits into the human body, and its bacteriological study. Jpn. Med. World 6, 299-304.
Olin, G. (1942). Occurrence and mode of transmission of in Sweden. Acta Pathol. Microbiol.Immunol.Scand. 19, 220-247.

Olsufiev, N. G. (1963). “Tularemia,” in Natural Foci of Human Infections, ed. E. N. Pavlovsky (Jerusalem: Israel Program for Scientific Translations), 127-163.

Olsufiev, N. G., Emelyanova, O. S., and Dunaeva, T. N. (1959). Comparative studies of strains of B. tularense in the old and new world and their taxonomy. J. Hyg. Epidemiol. Microbiol. Immunol. 3, 138-149.

Owen, C. R., and Buker, E. R. (1956). Factors involved in the transmission of Pasteurella tularensis from inoculated animals to healthy cagemates. $J$. Infect. Dis. 99, 227-233.

Paddock, C. D., and Telford, S. R. (in press). Through a glass, darkly: the global incidence of tick borne diseases. Institute of Medicine, Lyme disease: State of the Science. http://www. iom.edu/ /media/Files/Activity\%20 Files/Disease/TickBorne/01-GlobalIncidence-of-Tick-borne-disease.pdf

Parker, R. R. (1934). Recent studies of tick borne diseases made at the U.S. Public Health Service Laboratories at Hamilton, MT. Proceedings of 5th Pacific Science Congress 5, 3367-3374.

Parker, R. R., Spencer, R. R., and Francis, E. (1924). Tularemia infection in ticks of the species Dermacentor andersoni stiles in the Bitterroot Valley, Montana. Public Health Rep. 39, 1057-1073.

Parker, R. R., Steinhaus, E. A., Kohls, G. M., and Jellison, W. L. (1951). Contamination of natural waters and mud with Pasteurella tularensis and tularemia in beavers and muskrats in the northwestern United States. Bull. Natl. Inst. Health 193, 1-161.

Pavlovsky, E. N. (1966). Natural Nidality of Transmissible Diseases. Urbana: University of Illinois Press.

Pearse, R. A. (1911). Insect bites. Med. Sentinel 3, 81-82.

Petersen, J. M., Mead, P. S., and Schriefer, M. E. (2009). Francisella tularensis: an arthropod-borne pathogen. Vet. Res. 40, 7.

Petrov, V. G. (1960). Experimental study of Dermacentor marginatus Sulz and Rhipicephalus rossicus Jak et Jak,
K. Ticks as vectors of tularemia. $J$. Parasitol. 46, 877-884.

Philip, C. B., and Jellison, W.L. (1934). The American dog tick, Dermacentor variabilis, as a host of Bacterium tularense. Public Health Rep. 49, 386-392.

Philip, C. B., and Parker, R. R. (1938) Occurrence of tularemia in the rabbit tick, (Haemaphysalis leporispalustris) in Alaska. Public Health Rep. 53, 574-575.

Pollitzer, R. (1967). History and Incidence of Tularemia in the Soviet Union: A Review. Bronx, NY: Institute for Contemporary Russian Studies, Fordham University.

Randolph, S. E., Gern, L., and Nuttall, P. A. (1996). Co-feeding ticks: epidemiological significance for tick-borne pathogen transmission. Parasitol. Today 12, 472-479.

Reese, S. M., Dietrich, G., Dolan, M. C., Sheldon, S. W., Piesman, J., Petersen, J. M., and Eisen, R. J. (2010). Transmission dynamics of Francisella tularensis subspecies and clades by nymphal Dermacentor variabilis (Acari: Ixodidae). Am. J. Trop. Med. Hyg. 83, 645-652.

Reintjes, R., Dedushaj, I., Gjini, A. Jorgensen, T. R., Cotter, B., Lieftucht, A., D’Ancona, F., Dennis, D. T., Kosoy, M.A., Mulliqi-Osmani, G., Grunow, R., Kalaveshi, A., Gashi, L., and Humolli, I. (2002). Tularemia outbreak investigation in Kosovo: case control and environmental studies. Emerg. Infect. Dis. 8, 69-73.

Schafer, C., Hahn, M., and Oschmann, P. (1999). "Tick ecology and epidemiology," in Lyme Borreliosis and Tick Borne Encephalitis, eds P. Oschmann, P. Kraiczy, J. Halperin, and V. Brade (Bremen: UniMed Verlag AG), 30-40.

Spielman, A., and Rossignol, P. A. (1984). "Insect vectors," in Tropical and Geographic Medicine, eds K.S. Warren and A. A. F. Mahmound (New York: McGraw-Hill), 167-183.

Svensson, K., Back, E., Eliasson, H., Berglund, L., Granberg, M., Karlsson, L. Larsson, P., Forsman, M., and Johansson, A. (2009). Landscape epidemiology of tularemia outbreaks in Sweden. Emerg. Infect. Dis. 15, 1937-1947.

Syrjala, H., Kujala, P., Myllyla, V., and Salminen, A. (1985). Airborne transmission of tularemia in farmers. Scand. J. Infect. Dis. 17, 371-375.

Telford, S. R., and Spielman, A. (1989). Enzootic transmission of the agent of Lyme disease in rabbits. Am. J. Trop. Med. Hyg. 41, 482-490.

Toyoshima, J., and Ohara, S. (1967). Tularemia acquired from a flying squirrel. Ann. Rep. Ohara Gen. Hosp. 11, 7-9.

Triebenbach, A. N., Vogl, S. J., LotspeichCole, L., Sikes, D. S., Happ, G.M., and Hueffer, K. (2010). Detection of Francisella tularensis in Alaskan mosquitoes (Diptera: Culicidae) and assessment of a laboratory model for transmission. J. Med. Entomol. 47, 639-648.

Vogler, A. J., Birdsell, D., Wagner, D. M., and Keim, P. (2009). An optimized, multiplexed multi-locus variablenumber tandem repeat analysis system for genotyping Francisella tularensis. Lett. Appl. Microbiol. 48, 140-144.

Yeatter, R. E., and Thompson, D. H. (1952). Tularemia, weather, and rabbit populations. Bull. Illinois Nat. History Survey 25, 351-382.

Conflict of Interest Statement: The authors declare that the research was conducted in the absence of any commercial or financial relationships that could be construed as a potential conflict of interest.

Received: 30 November 2010; accepted: 29 December 2010; published online: 28 January 2011.

Citation: Telford SR III and Goethert HK (2011) Toward an understanding of the perpetuation of the agent of tularemia. Front. Microbio. 1:150. doi: 10.3389/ fmicb.2010.00150

This article was submitted to Frontiers in Cellular and Infection Microbiology, a specialty of Frontiers in Microbiology.

Copyright (C) 2011 Telford III and Goethert. This is an open-access article subject to an exclusive license agreement between the authors and Frontiers Media $S A$, which permits unrestricted use, distribution, and reproduction in any medium, provided the original authors and source are credited. 